\title{
A Child With Malrotation and Severe Metabolic Alkalosis
}

\author{
Seyed Mohsen Dehghani ${ }^{\mathrm{a}, \mathrm{b}, \mathrm{e}}$, Naqi Dar ${ }^{\mathrm{b}}$, Mahmood Haghighat ${ }^{\mathrm{b}}$, Mohammad Hadi Imanieh ${ }^{\mathrm{a}, \mathrm{b}}$, \\ Karmella Kamalic, Hamid Reza Foroutan ${ }^{\mathrm{d}}$
}

\begin{abstract}
Malrotation is an incomplete rotation and fixation of the intestine that occur during fetal development. It is a predisposing factor for development of volvulus. The most common presentation is bilious vomiting and other symptoms of gastrointestinal obstruction during infancy. In children may have a more prolonged course with episodic attacks of abdominal pain, vomiting, dehydration, malabsorption and poor weight gain from chronic intermittent lymphatic obstruction. Here a case of malrotation with dehydration, severe metabolic alkalosis ( $\mathrm{pH}$ above 8.06) is reported in a school age child, who was survived with appropriate management.
\end{abstract}

Keywords: Malrotation; Metabolic alkalosis; Child

\section{Introduction}

Malrotation is defined as a failure of normal rotation of any

Manuscript accepted for publication August 23, 2011

\footnotetext{
${ }^{a}$ Shiraz Transplant Research Center, Shiraz University of Medical Sci ences, Shiraz, Iran

${ }^{\mathrm{b}}$ Gastroenterohepatology Research Center, Shiraz University of Medical Sciences, Shiraz, Iran

${ }^{\mathrm{c} R a d i o l o g y}$ Department, Shiraz University of Medical Sciences, Shiraz, Iran

${ }^{\mathrm{d}}$ Pediatric Surgery Department, Shiraz University of Medical Sciences, Shiraz, Iran

${ }^{\mathrm{e}}$ Corresponding author: Seyed Mohsen Dehghani.

Email: dehghanism@sums.ac.ir
}

doi:10.4021/ijcp101e portion of the gastrointestinal (GI) tract. It also implies abnormal fixation, which is a predisposing factor for the development of volvulus [1].

Malrotation is a true surgical emergency when associated with volvulus or intestinal obstruction and demands expeditious diagnosis and surgical intervention. In infancy, the most common presentation is bilious vomiting and other symptoms of GI obstruction [1-3]. Children, who present beyond infancy, may have a more prolonged course with episodic attacks of abdominal pain, vomiting, or malabsorption and poor weight gain from chronic intermittent lymphatic obstruction $[2,3]$.

Here in a case with malrotation and severe metabolic alkalosis, appearing to be incompatible with life, but survived is reported.

\section{Case Report}

The patient is a 12 year old boy that was well up to 3 years of age, after that he presented with epigastric abdominal pain, nausea and nonbilious vomiting with stereotypical pattern, 4 episodes per year. In previous admissions, workups for metabolic disorders, GI disorders (upper GI series and follow through, barium enema and abdominal ultrasonography) and central nervous system problems (brain computed tomography scan and magnetic resonance imaging) were done which were not conclusive. Thus he was treated as a case of idiopathic cyclic vomiting syndrome with propranolol, but without significant improvement. From one month prior to this episode, he developed epigastric abdominal pain, nausea, bilious vomiting, low grade fever, anorexia and about 8 Kilograms weight loss. He was referred to our center for further evaluation.

At the time of admission in our ward, he was a temperature of $37.9^{\circ} \mathrm{C}$, pulse rate of $128 /$ minute, and blood pressure of $80 / 60 \mathrm{mmHg}$ with orthostatic hypotension. He had sunken eyes, dried oral mucosa, tongue and skin. Also he had abdominal tenderness at the epigastric and periumbilical area without rebound tenderness and bowel sound were hyperactive. He was drowsy and lethargic.

Initial laboratory workups including complete blood 
Table 1. Serial Blood Gas Analysis of Patient With Malrotation and Severe Metabolic Alkalosis

\begin{tabular}{lccccccc}
\hline & $\mathbf{1}$ & $\mathbf{2}$ & $\mathbf{3}$ & $\mathbf{4}$ & $\mathbf{5}$ & $\mathbf{6}$ & $\mathbf{7}$ \\
\hline $\mathrm{pH}$ & 8.06 & 7.90 & 7.60 & 7.51 & 7.43 & 7.52 & 7.40 \\
$\mathrm{PCO} 2 \mathrm{mmHg}$ & 26.8 & 35.4 & 34.9 & 33.4 & 42.4 & 25.3 & 32.4 \\
$\mathrm{HCO} 3 \mathrm{mmol} / \mathrm{L}$ & 74.1 & 68.7 & 33.5 & 26.9 & 28.5 & 20.3 & 20.1 \\
$\mathrm{BE} \mathrm{ecf} \mathrm{mmol} / \mathrm{L}$ & 56.9 & 49.5 & 11.7 & & & -1.6 & -3.6 \\
$\mathrm{BE} \mathrm{mmol} / \mathrm{L}$ & 56.8 & 48.4 & 12.8 & 5.3 & 4.4 & 0.7 & -3.2 \\
$\mathrm{BB} \mathrm{mmol} / \mathrm{L}$ & 104.8 & 96.4 & 60.8 & 52.3 & 53.2 & 48.7 & 44.2 \\
\hline
\end{tabular}

count, erythrocyte sedimentation rate, $\mathrm{C}$ reacting protein, blood and urine cultures, serum amylase and lipase levels, and liver function tests were normal. Other laboratory findings were included serum sodium $127 \mathrm{meq} / \mathrm{L}$, serum potassium $3 \mathrm{meq} / \mathrm{L}$, blood urea nitrogen $54 \mathrm{mg} / \mathrm{dL}$, serum creatinine $1.9 \mathrm{mg} / \mathrm{dL}$, alkaline urine with $2+$ ketonuria and specific gravity of 1.016. Initial blood gas analysis showed severe metabolic alkalosis ( $\mathrm{pH}$ : 8.06, PCO2: 26 mmHg, HCO3: 75 $\mathrm{mg} / \mathrm{dL}$ ) (Table 1).

Esophagogastroduodenoscopy revealed severe erythema in lower third of esophagus, mucosal erythema of body, an ulcer on the lesser curvature and also erythematous mucosa of duodenum.

Upper GI series with small bowel follow through didn't show the $\mathrm{C}$-shaped configuration of duodenum with dilated third portion and an abrupt oblique indentation of this por- tion caused by compressive effects of the peritoneal bands. Small amount of contrast was seen in distal bowel loops suggesting high grade partial obstruction of the third portion of duodenum (Fig. 1).

In abdominal ultrasonography the stomach was over distended and fluid filled, the first and second parts of the duodenum were dilated with to and fro pattern peristalsis, but third part of duodenum was not seen.

After correction of dehydration and metabolic alkalosis he was transferred to pediatric surgery ward. He underwent laparatomy and had malrotation with adhesion band, duodenal hypertrophy, and multiple mesenteric lymphadenopathy. Lads' procedure was done for him.

\section{Discussion}

Table 2. Relationship Between the Arterial $\mathrm{pH}$ and $\mathrm{H}+$ Concentration in the Physiologic Range [9]

\begin{tabular}{cccc}
\hline $\mathbf{p H}$ & $(\mathbf{H}+), \mathbf{n m o l} / \mathbf{L}$ & $\mathbf{p H}$ & $(\mathbf{H}+), \mathbf{n m o l} / \mathbf{L}$ \\
\hline 7.80 & 16 & 7.00 & 100 \\
7.70 & 20 & 6.90 & 125 \\
7.60 & 26 & 6.80 & \\
7.50 & 32 & & \\
7.40 & 40 & & \\
7.30 & 50 & \\
7.20 & 63 & \\
7.10 & 80 & \\
\hline
\end{tabular}



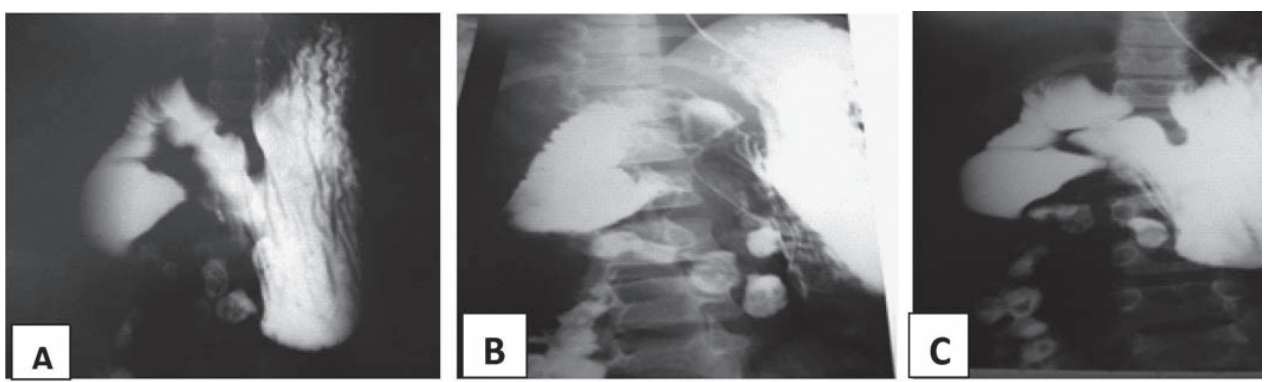

Figure 1. A-C: Upper gastrointestinal series: the third portion demonstrates dilation with an abrupt oblique indentation caused by compressive effects of the peritoneal bands.

The mid gut (distal duodenum to mid-transverse colon) begins to elongate and progressively protrudes into the umblical cord until it lies totally ouside the confines of the abdominal cavity. As the developing bowel rotates in and out of the abdominal cavity, the superior mesentric artery, which suplies blood to this section of gut, acts as an axis. The duodenum become fixed to the posterior abdominal wall before the colon is completely rotated. The most common type of malrotation involves failure of the secum to move into the right lower quadrant [3]. In addition, bands of tissue (Ladds bands) may extended from the cecum to the right upper quadrant, crossing and possibly obstructing the duodenum. Symptom are caused by intermittent volvulus or duodenal compression by Ladds bands or other adhesive bands affecting the small and large bowel. The incidence of malrotation is estimated to be approximately 1 in 500 live birth, the majority of patients will presents within the first month of life with volvulus [1]. Older infants present with episodes of recurrent abdominal pain that can mimic colic. Malrotation in older children may present with recurrent episodes of vomiting, abdominal pain, or both and may have a more prolonged course and even malabsorption and poor weight gain, protein-losing enteropathy associated with bacterial overgrowth [2]. Twenty five to fifty percent of adolescents with malrotation are asymptomatic, adolescents who become symptomatic present with acute intestinal obstruction or history of recurrent episodes of abdominal pain, bilious vomiting with less frequent diarrhea [4].

During acute intestinal obstruction the patients may lose gastric fluid, via either emesis or nasogastric suction also may develop dehydration mostly due to impaired oral fluid intake. Electrolyte disturbances, particularly hypokalemia and metabolic alkalosis, are also common. These complications can be prevented by judicious use of appropriate replacement therapy $[5,6]$.

At time of admission our patient had severe dehydration with severe metabolic alkalosis that seems to be incompatible with life. Repeated serial blood gas analyses confirmed severe metabolic alkalosis.

A normal $\mathrm{pH}$ is between $7.35-7.45$. There is an inverse relationship between the $\mathrm{pH}$ and the hydrogen ion concentration (Table 2). When the hydrogen ion concentration decreases, the $\mathrm{pH}$ increases and when the hydrogen ion concentration increases, the $\mathrm{pH}$ decreases. At a $\mathrm{pH}$ of 7.40 the hydrogen ion concentration is $40 \mathrm{nmol} / \mathrm{L}$. Maintaining a normal $\mathrm{pH}$ is necessary because hydrogen ion is highly reactive and likely to combine with proteins, altering its function.

The previously accepted $\mathrm{pH}$ which is compatible with life is 6.80 to 7.8 with hydrogen ion concentration in range of 16 to $160 \mathrm{nmol} / \mathrm{L}$ [7-9].

In reviewing the literature there is no reported case who survived with $\mathrm{pH}$ more than 8 up to now. Our case survived despite $\mathrm{pH}$ of 8.06. During a six months follow up he had not any episodes of vomiting or abdominal pain.

We concluded in each case with bilious vomiting and dehydration, small bowel obstruction (complete or partial) or malrotation should be considered. Not all cases with blood $\mathrm{pH}$ more than 8 are fatal. We think with appropriate management, patients with $\mathrm{pH}$ more than 8 , may have chance to survive.

\section{References}

1. Strouse PJ. Disorders of intestinal rotation and fixation (“malrotation"). Pediatr Radiol. 2004;34(11):837-851.

2. Spigland N, Brandt ML, Yazbeck S. Malrotation presenting beyond the neonatal period. J Pediatr Surg. 1990;25(11):1139-1142.

3. Millar AJ, Rode H, Cywes S. Malrotation and volvulus in infancy and childhood. Semin Pediatr Surg. 2003;12(4):229-236.

4. Pickhardt PJ, Bhalla S. Intestinal malrotation in adolescents and adults: spectrum of clinical and imaging features. AJR Am J Roentgenol. 2002;179(6):1429-1435.

5. Mehall JR, Chandler JC, Mehall RL, Jackson RJ, Wagner CW, Smith SD. Management of typical and atypical intestinal malrotation. J Pediatr Surg. 2002;37(8):11691172.

6. Taylor D, Durward A. Pouring salt on troubled waters. 
Arch Dis Child. 2004;89(5):411-414.

7. Hills AG. pH and the Henderson-Hasselbalch equation. Am J Med. 1973;55(2):131-133.

8. Schwaderer AL, Schwartz GJ. Back to basics: acidosis and alkalosis. Pediatr Rev. 2004;25(10):350-357.

9. Rose BD, Post TW. Clinical physiology of acid-base and electrolyte disorders. Fifth edition, Mc Graw Hill 2001; 305-306. 